\title{
3D AND 4D MODELLING IN BUILDING SITE WORKING CONTROL
}

\author{
M. Lucarelli ${ }^{1}$, E. Laurini ${ }^{1}$, P. De Berardinis ${ }^{1}$ \\ ${ }^{1}$ Department of Civil, Architectural Construction and Environmental Engineering, University of L'Aquila, Italy
}

\section{Commission II}

KEY WORDS: building site, historic center, safety, 4D management, advanced layout , hbim

\begin{abstract}
The purpose of this contribution is to describe the use of the HBIM method for the management of the restoration building site applied to a historic building in the heart of the historic center of L'Aquila. The construction is located in a densely constructed area and it is characterized by a high spatial complexity with various types of limitations including: small external and internal spaces and interferences due to neighboring construction sites. The proposed method involves a particularly detailed organization of the construction site, simultaneously planning both the development of the working and the safety in order to have more transparency and more control of the information shared among stakeholders. This method consists in planning the Gantt diagram from general to detailed level, according to certain parameters that will be cross-examined and checked regurarly. A screening step has been carried out regarding the current situation, the proceedings to be undertaken and the stakeholders to be included. Thank to this, it has been possible to have automated processes to control not only geometrical interferences but also the ones related to the completion of the work in the interest of enhancing the risk management. Due to a 3D and 4D BIM modelling, there are been found advanced layouts and some timeliners that have allowed a rigourus control of the building process, particularly in the case of precise working and potencial changes that are common in building sites of this type.
\end{abstract}

\section{PROJECT BACKGROUND}

The purpose of this contribution is to describe the use of the HBIM (Heritage Building Information Modeling) method for the management of the restoration building site (Garagnani, 2015). This particular type of building site presents many critical problems and conflicts of various nature, placing itself in a very particular context and HBIM represents an innovative methodology with which it is possible to achieve a more advanced management process that enable an updated control of construction site conformations (Salzano, 2015). Unlike a "common" building site for a new construction, the restoration one is characterized by a continuous exchange of information because there may be breakthrough not highlighted in the analysis of the work. Therefore, as if it were a fluid, we will have a continuous interrelationship among some phases of the life cycle such as: detailed drawing, planning / documentation of works and building site logistics. "Because in the intervention of the existing buildings, the constrution area is no longer the place of the pure execution of working but the theather where action, technique and scientific thinking are connected under the guidance of a creative, vigilant, cultured leading conducted by a Project Manager or a General Contractor" (De Berardinis et al., 2018). It is proposed the application of the method for a historic building in the heart of the historic center of L'Aquila, which suffered enormous damage after the earthquake in 2009 and now it is among the largest building sites in Europe. The construction is located within the historical texture, in a densely constructed area and characterized by a high spatial complexity. There are various types of limitations including: small external and internal spaces, interferences due to neighboring construction sites, very narrow width of the streets with consequent problems not only for the passage of heavy vehicles, but also for any overlap of flow between the building site, emergency escape / exodus routes and pedestrian paths.
These critical issues are connected to the historical centre in full rebirth and repopulation and it is not possible to have a single-service road for reconstruction work. The building site, therefore, presents a considerable amount of problems that must be identified, resolved and updated regularly with a steady sharing of information among stakeholders. The BIM coordinator will be the key role in the trasmission of information. He will help the BIM Manager and he will lead workset to articular enteties, because everyone will receive not the whole amount of the datas but only the specific ones for his area in order to prevent the blurring of roles and responsabilities (Ferrara, Feligioni, 2016).

\section{CASE STUDY DESCRIPTION}

The building on which is applied the HBIM method for the management of the construction area, is located in the historic center of L'Aquila, in Via Garibaldi and it is better known as birthplace of the famous writer Laudomia Bonanni (1907-2002), as indicated by commemorative plaque placed in the front facade of the building. Most likely, it dates back to 19th century, although the first establishment dates back to 14th century, according to some blueprints. The building has 3 floors where traditionally the first floor is intended to the noble family. The resulting prospectus highlight this division in three stringcourses from which are originated the false balcony of the windows situated at the end of the prospectus. The building with three floors, a basement and a practicable garret consists of vertical supporting structures in mixed stone-mansory while the horizontal ones are made up of stone or brick vaulting ceilings and I-beams and large perforated blocks floors (Fig. 1).The roof, dated back to a 1990's restoration, consists of styrofoam slabs and ribs and a reinforced concrete curb. The restoration interventions occurred in the 1990 's included all the supporting structures of the building 
providing some subfoundations and the replacement of some floors. Due to the earthquake of the 6th of April 2009, the building suffered instability with moderate/severe damage pattern without collapse: Every wall had diffuse and severe cracks which in many case, included the vaulting ceilings above. It has been highlighted the absence of toothing of the wall bays and of the connection among walls, which caused the detachment of the horizontal structures. The lintels and the windows were affected dy horizontal and vertical split. Detachment of plaster concerned all the walls. Visual probing were conducted on the horizontal and vertical structures through the removal of the plaster and through endoscopic inspection which have pointed out the limited presence of space inside. The project,so, were about seismic retrofitting of the supporting structures and of the horizontal elements, in according to NTC 2008, in effect at the time of the planning. In the project, the main established measures taken to consolidate the structure are:

- strenghten the wall bays through of cement and glass reinforced polymeric fibres injections regularly done on the wall.

- strenghten of the openings through the realization

of new flange plate and the remake of the existing ones using steel bars bolted among them.

- install steel tie-beams anchored by steel plates to the walls.

- it is provided for stabilization of the brick vaulting ceilings, after the removal of the flooring, the realization of cement abutment and the application of a net made in composite material in carbon fiber applied to the vaulting ceilings by carbon ribbons embedded with anti-shrinkage cement or epoxy resin, the whole thing smothered by a cape of fiber-reinforced cement.

The intervection is completed by lightened filling with light cellular concrete and screed with smothered welded steel mesh. (Fig. 2 , Fig. 3).

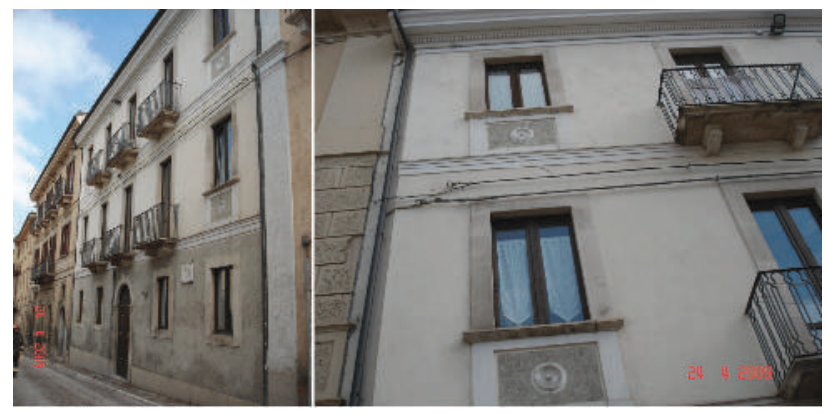

Figure 1: Pre-working condition, after earthquake 2009

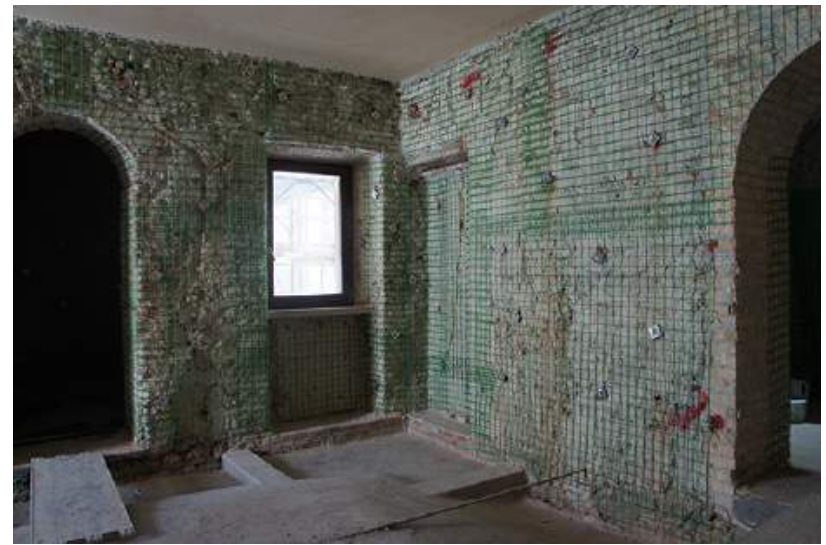

Figure 2: Reinforcement of walls with a fiberglass mesh and steel bridgings

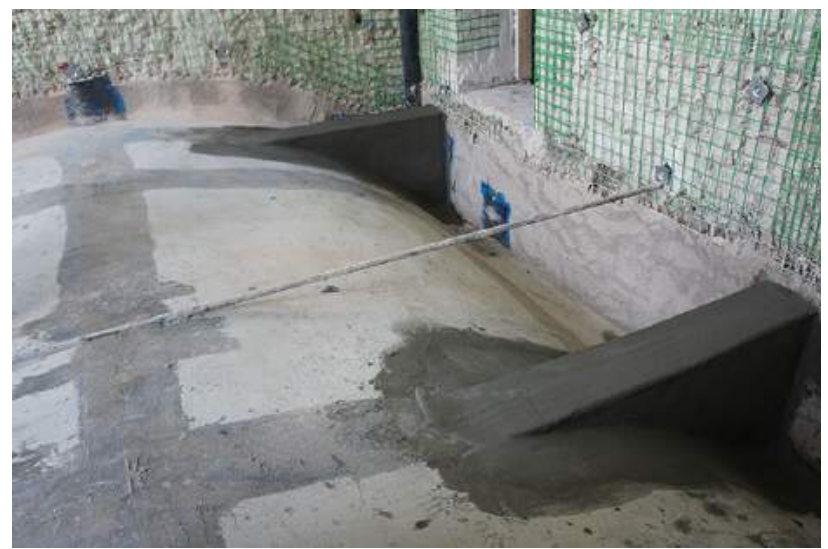

Figure 3: Reinforcement of the vaulting ceilings with carbon fiber bands and solid brick spurs.

\section{RELATED WORKS}

Because of the potentiality of the BIM method and its large spread in all the aspects of the building life cycle, the large companies and professionals have already undertaken the implementation of this method. Unfortunately, some difficulties in the applying the BIM method to the existing heritage are pointed out both by the designer and by the administration. This vulnerability is considered by rule UNI 11337. It established mandatorily the application of the BIM method for the public worksand for works with a value equal or more to 100 milions $€$,from January 2019. In the planning of the building site, all the organitation mistakes / superficialities or the misuse of the clash detection emerge and they can nullify the efforts done for the adoption of the BIM method. Even more delicate, it is the planning of the safety because it is based on the individuation and the analysis of the interferences and on the abilites to reduce the risks for workers as much as possible. Other issues that even now are found in the building area, are: " the project of the build sites with particular detailed study of the needed provisional works; the planning of the activities and their coordination, the correct sequence and the compresence of activities in order to avoid interferences; the comunication with the personnel to garantee the knowledge of the risks in the building area and how to prevent them thanks to the adoption of safe behaviour (Bragadin, 2012). To this day, having available a lot of digital and methodological tools, the enhancing of the risk management can not be based only on a classical security plan and coordination which often it is not studied by the workers but, thanks to creating graphics of the work phases with the Personal protective equipment (PPE), the storage of materials, and the possible obstacles present in the build area, the personnel knows what and how to do the working, even before the construction site starts. (Sadeghpour et al.,2006). In addition, there is a high control of the supervision of the working, thanks to which is possible to compare the 3D BIM model to the reality in every way and immediately. As it will be explained later, the porpouse of the research is the detailed study of the operation according to the materials to use, the employed personnel, the documents to receive and to deliver throughout the workings in order to have an update and detailed work progress in a very problematic situation like the one hit by natural disasters. 


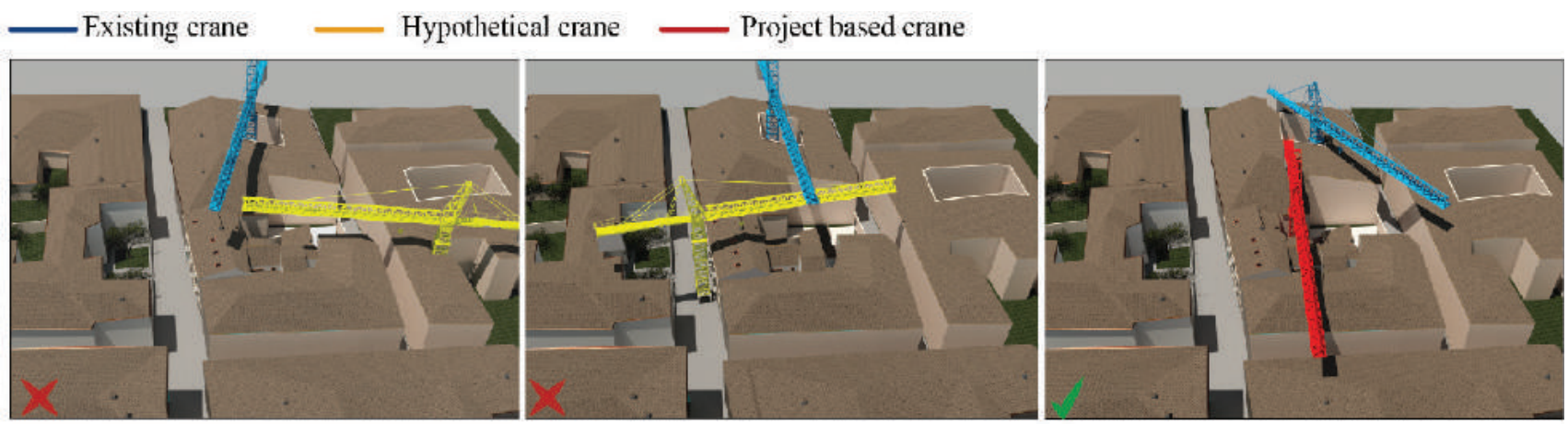

Figure 4: Theories and placement of the cranes

\section{TOOLS AND METHODS}

The method adopted for the design of the site is called ADAP (As Detailed as possible) and aims to have a high standard of quality of the project and safety on the construction site, trying to reduce as much as possible costs and time (Lucarelli et al.,2018). In this way, it is possible to increase qualitatively the whole cycle of workings not only in favor of the construction company and of the architect, but also in favor of the costumer that will not meet changes during the workings. The method consists in:

- identify the best location for the tower crane (Fig. 4). Due to the position in a full restoration historic center, it is possible to use the cranes already arrrenged on site.

For this purpouse, three hypotheses:

1- Shared crane: the adjacent building area had available a job of the crane that covered our building area but it could not be used because of a lack of collaboration.

2- Raised crane: it has been designed to allow the passage of small machinery and pedestrians in safety but it has been refused for logistic and size reasons. The street in front of the enter of the building site is really important for the general traffic. If the raised crane had been located, it would have been obstacles not only for the adjacent building sites but also for the citizens.

3- Inside crane: thanks to a $360^{\circ}$ visuals and to the rigorous congruity of the model to the reality, it has been decided to place the crane in the courtyard. It has been studied the areas for the realization of the base and for its placement in order to allow mobility in the courtyard. For its size, the crane could be available to cover the adjacent building site.

- working from top to bottom of the building. It proceedes in the opposite way respect to a building site of new construction. Due to the particular situation and the high risk of structural collapse both inside and outside the building, it is necessary working for areas. The strategy for identifying the areas will follow two course: vertical and horizontal. The former, because working will not be placed in column, espacially the ones which will include high mobility or vibrations. The latter, because it will be chosen to work in layers. In this way, once the upper floor will be in safety, there will be no dangers to carry out the activities on the floor below (Kiviniemi et al., 2011). Related to the supply of materials, it will be opportune to not create many storages because they could reduce the space or create obstacles for the workers. (Fig. 5).
- arranging activities so that they do not overlap and the workers are in different parts of the building, studying specific working routes for the teams and appropiate escape routes. Because of the continous evolution of the urban fabric, it will be necessary to upadate the escape route in relation to the routes prepared for the building which can be interrupted because of working creating obstacles to reach the nearest rally points or the personal protective equipments (PPEs). For this reason, various escape routes were studyed in relation to the specific work and it has been possible highlight the fastest and safest escape route thanks to a $3 \mathrm{D}$ model with all the data of the building site. Due to its location in the historic center, workers have available only one escape route which is the front door of the building. This could be problematic in the case the front door can not be used. Various theory has been analysed but the best one is using the stairs among the scaffoldings. In this way, from every floors of the building, workers can reach the rally points. In the specific case, it has been examined in depth one of the most difficult work: stabilizations of the vaulting ceiling. This one is placed on the third floor and it have only one opening to air the room in the interest of confort and well-being of the workers. Working strictly with BIM, it has been identifing a specific working process and then,it was created a graphic with all the activities including the existing risk and hoe to reduce them. Because of the delicacy of the working, it will be essential to know the exact working process from the start, in order to avoid interferences with other activities. (Fig. 6) (Vacharapoom et all.,2018).

- planning the Gantt diagram from general to detailed level, according to certain parameters. In the general level, there will be an awareness of how, when and who carries out specific activities and then, these information will be included in the diagram. This practice allows a more balanced distribution of costs and efforts. In the detailed level, we will have an identification of " $n$ " stages of development (S.o.D.) that will be considered as the containers of all the information of the construction site in those specific periods of time. In case of variant or delay of the work, it will be the designer's ability to reorganize all the works inside the stage of development in order to avoid delays of the final deadline of the works. Everything will be done with the respect of the parameters of safety and organization of the activities used for the planning of the Gantt. (Ku et all., 2011). In addition, thanks to the use of this method, it will be possible to update the security plans and to control the existing risk in the building site. 

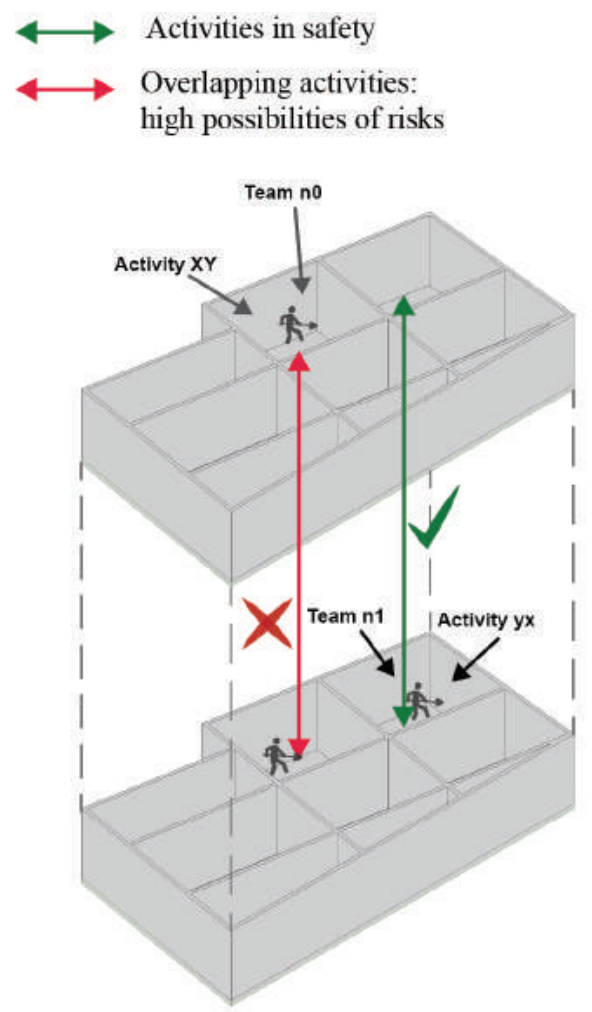

Figure 5: Arragement of the work

Before making a parametric modelling, mapping process was realized for some workflow steps such as: technical documentation (using charts like WBS, OBS, RAM, RACI, AON), site analysis and building site management. In particular, a distinction among OBS -RAM -RACI has been carried out and it was

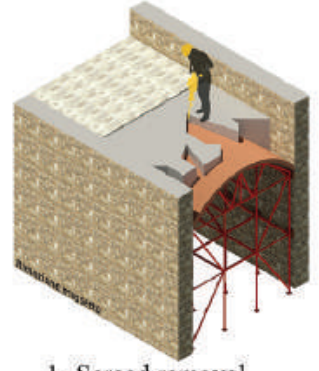

1- Screed removal

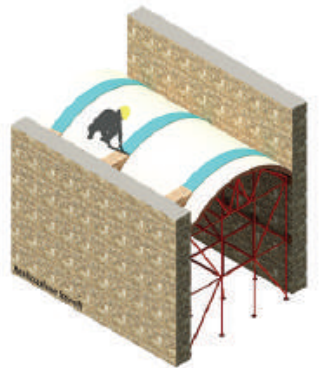

5- Solid brick spurs realization

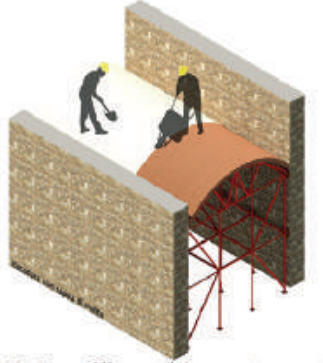

2- Levelling with mortar coat

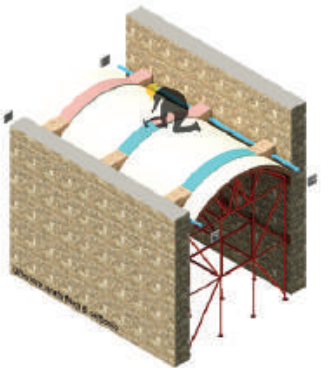

6- Additional carbon fiber layer

studied who have responsabilities and in what proportion.Inside these processes, there will be the right strategy to follow, the documents to be received and delivered, the professionals appointed and the software used. Given the complexity of the management and the large amount of information, the figure of the BIM Manager will be fundamental. Thanks to a 3D BIM model, advanced layouts have been identified. They show not only the change of conformation of the building site but also a time schedule linked to the layouts (4D management) in order to have the possibility to evaluate the progress of the work in relation to the planning: we are on a certain day, we look at the model, then at the reality and we deduce the necessary conclusions, so we will need checkpoints to monitor the quality of the work done. Finally, the results must be shared with all the actors involved in the process. Thanks to a 4D model, it could be possible to examine in depth specific working process through step work. As a result of a timeline, workers will see the exact execution to follow and it will be useful to have a confrontation with the customers. (Sulankivi et al., 2010). This confirms the main role of interoperability of BIM: using various tools and technologies like virtual reality or augmented reality, the customer could be captivated in the the process. The close relationship between work and time has allowed us to keep the site under control but also to manage the supply of the material in a better way. Especially considering the dimensions available, it is essential to update and modify the area for the storage of materials, identifying a permanent area and another temporary one. This last one is defined by small dimensione e by a continous change of position inside the building, placing them where there will be the activities. For all it is been said before, thank to the adoption of the HBIM method, the advantages achieved in this phase are: a better execution and rapidity of the work activities, the respect of active and passive investements of the main contractor and a comfort for the workers.

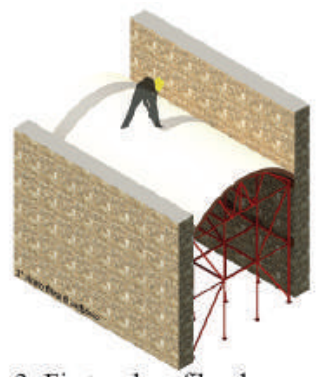

3- First carbon fiber layer

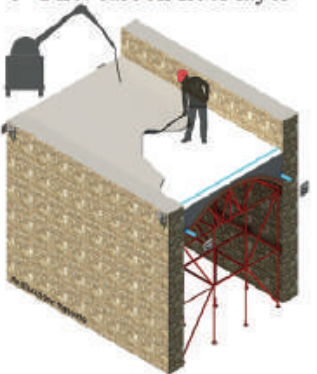

7- Screed realization

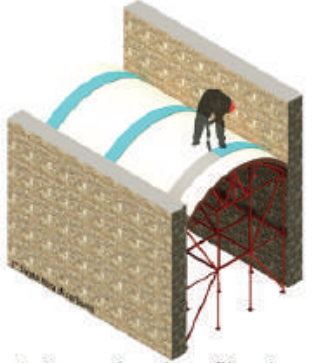

4- Second carbon fiber laye

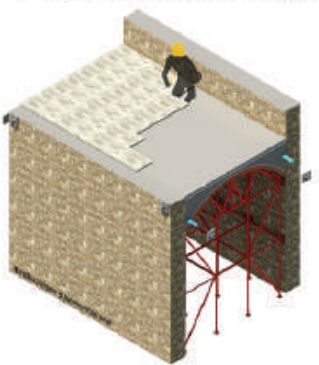

8- Paving realization

Figure 6: Working process for the vaulting ceilings 

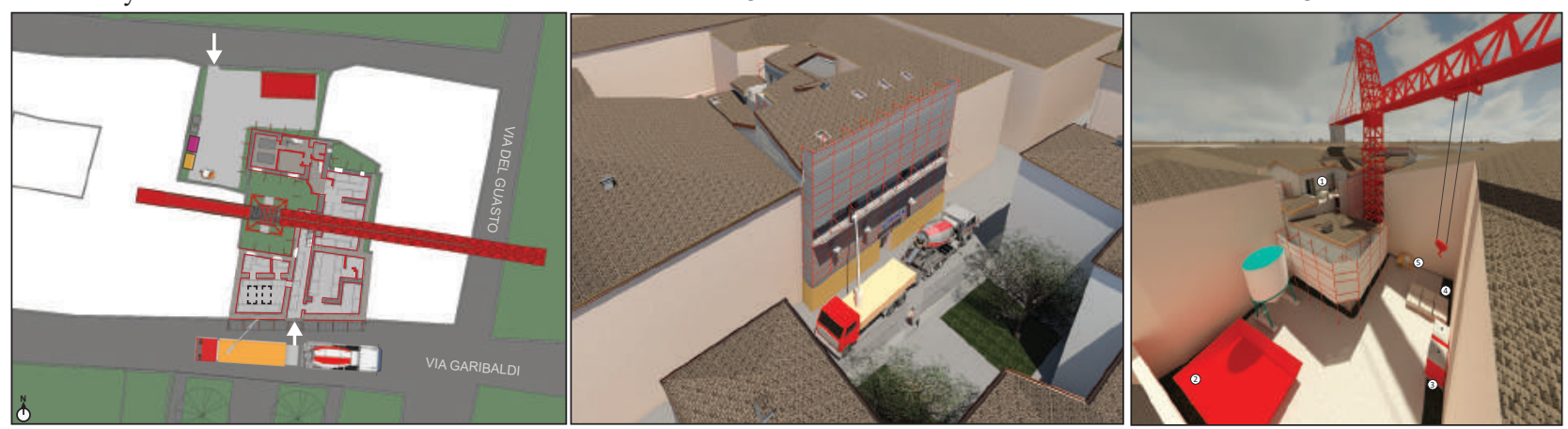

Legenda

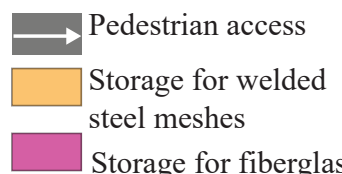

\section{Previous offices}

$\square$ Interior scaffolding

Storage for fiberglass Screed removal
Legend:

1- Temporary materials storage

2- Resulting materials storage

3- Toilet facilities

4- Materials storage

5- Building site machineries

Figure 7 : Evoluted Layouts

\section{ACHIEVED RESULTS}

The method explained before can not be enclosed in a simple 2D drawing which only take a photograph of a single moment of a series of processes. In order to integrate the safety planning and to increase risk management, the majority of the activities were graphicized, the risk values of them were identified and subsequently, they were mitigated. In this way, a graphic PSC is obtained that is much more intuitive and practical for foreign workers than the common safety and coordination plan. (Fig 6, Fig. 7, Fig. 8). In this way, there are many benefits: it is possible to focus attention on particularly sensitive moments, analyze them on the model from different angles and understand the existing risk factors facilitating the safety checks because there must be congruence between what it is indicated in the model and what is realized in reality (a peculiar characteristic of HBIM is L.o.R. Level of reliability, an accurate correspondence between the 3D model and reality).
Moreover, with the same integrated parametric model, during construction, variants were carried out. These variants were performed by following the procedures taken for the other actvities of the building site. Working only in BIM, it is not possible to receive and execute the activity directly because the point of arrival for the building site management is the starting point for the facility management. For this reason, it has been identified a specific process and the new activities were added in a certain period of time in order to avoid interferences with works / initial strategies. Operating in this way, the principle of interoperability between the stakeholders is fully respected thank to continuous communication and information sharing, through the IFC format. The adoption of an integrated and shared itinerary will allow an advanced management of data, a better economic planning simulation for the realization and for the maintenance and greater confidence in the actors of construction process.
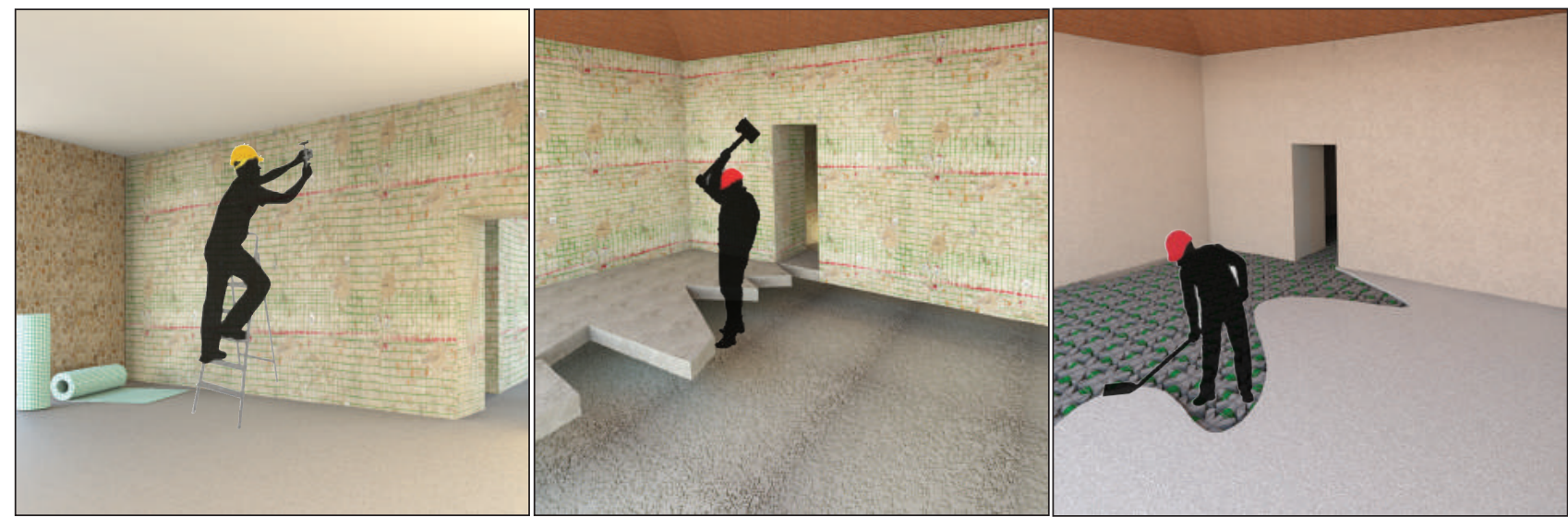

Figure 8: From the left, application of fiberglass- screed removal 


\section{CONCLUSION}

Unfortunately, being in its beginning, the BIM / HBIM method is confused with a simple three-dimensional modeling and not as a set of building information (BIM Washing theory) (Fig. 9). As described above, the proposed method reveals a great solution for working in the restoration building sites which represents about the $90 \%$ of italian real estate. As the result of application of the method to a real case, it could be tested and eventual weak points could be solved. Therefore, in addition to a considerable commitment by the designers, who will be submit to continuous training in the field of Building Information Modeling, there should be the foresight and complicity of the contracting authority with the BIM manager because he has the information control and managementof the whole process and he will be a bridge of knowledge between the building site and the contracting authority (Papadonikolaki et al.,2015). The last requirement is to fill the gap of regulations in our country that often create confusion about roles and tasks, slowing down, partly, the application of the method in Italy, especially comparing it to the rest of the world. The hope is that BIM can be a valid methodology not only for professional figures and enterprices, but also for the community in emergency situations such as reconstructions of cities or large areas. In fact, looking at the disastrous events of recent years such as earthquakes, floods or collapses, the field of application of this method is decidedly notable in all the life cycle of the building.

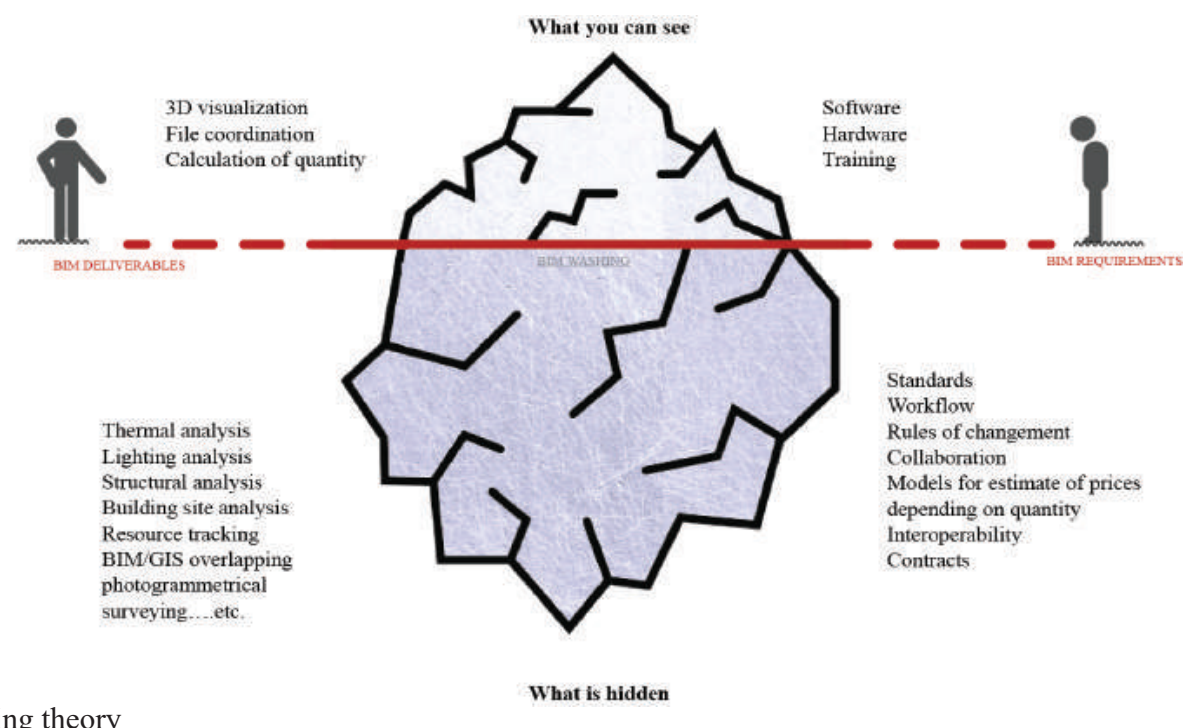

Figure 9: BIM washing theory

\section{REFERENCES}

Bragadin, A. 2012. Sicurezza e innovazione nel cantiere di recupero edilizio: l'approccio building information modelling. In ricerche e progetti per il territorio,la città e l'archiettura, numero 5 .

De Berardinis, P., Di Giovanni,G., Laurini, E. Rotilio, M., 2018. Progettare l'organizzazione del cantiere di recupero nell'ambito della ricostruzione post sismica all'Aquila. In: 6th Convegno Internazionale ReUSO, Messina, 1489-1500.

Ferrara, A. Feligioni, E. 2016. BIM e Project Management, Dario Flaccovio Editore, 16-25.

Garagnani, S., 2015. HBIM nell'esistente storico Potenzialità e limiti degli strumenti integrati nel recupero edilizio. In: Ingegnio 36, 1-5.

$\mathrm{Ku}, \mathrm{K}$, Mills, T.,2011. Research Needs for Building Information Modeling for Construction Safety. In: International proceedings of Associated Schools of Construction. 45th Annual Conference, Boston.
Lucarelli, M., Laurini, E., Rotilio, M., De Berardinis. P., Metodo BIM: gestione dei cantieri edilizi nei centri colpiti da calamità naturali. In: 6th Convegno Internazionale ReUSO, Messina, 2531-2542.

Papadonikolaki, E., Vrijhoef, R., Wamelink, F.,2015. A BIM-based supply chain model for AEC. In: WIT Transactions on The Built Environment, Vol 149,1-16.

Sadeghpour. F., Moselhi. O,. Alkass. S., 2006. Computer Aided Site Layout Planning. In: Journal of Construction Engineering and Management vol. 132.

Salzano, A., 2015. Sistema di Progettazione BIM Building Information Modeling. In Artstudio Paparo, 2-30.

Sulankivi, K., Kahkonen, K., Makela, T., Kiviniemi, M., 2010. 4D-BIM for construction Safety Planning CIB. In: International Congress Proceedings.

Vacharapoom, B., Sdabhon, B., 2018. An integrated safety management with construction management using 4D CAD model. In: Safety Science, No. 48. 